\title{
Editorial: Theatre's Itinerant Routes/Roots
}

\author{
CHARLOTTE M. CANNING
}

These four articles are very different in subject, geography, methodology and evidence. Despite these significant divergences, their presence in a single issue is fortuitous. What these articles offer as a single entity is an important reminder of how theatre is always concerned with and emerging from exchange and movement. Sometimes the movement is across global geopolitical boundaries; sometimes it is only across counties in a single nation. Sometimes the movement is the global circulation of ideas, and artists of very different cultures may be approaching similar subjects in similar ways although they have never met. Sometimes those routes may be traced on a map; sometimes they are roots only revealed as pathways through the transformative act of performance. Sometimes, of course, the movement is simply that of the body in representation. In all these essays the routes/roots involve challenges to collaboration and understanding, and results may come from achieving the goal of connection and/or from falling far short. Through comparing these articles with one another, we can enrich our own work as scholars and artists because they remind us to re-examine how we define even our most basic terms and assumptions.

Nic Leonhardt's article "'From the Land of the White Elephant through the Gay Cities of Europe and America": Re-routing the World Tour of the Boosra Mahin Siamese Theatre Troupe (1900)' demonstrates how global routes of transmission are not confined to a single historical moment. As part of a recent movement towards global and transnational theatre histories, Leonhardt takes up a recent Thai performance in Germany by Pichet Klunchun inspired by photographs of dancer Vaslav Nijinsky in the 1910 La danse siamoise. As Leonhardt researches Klunchun's work, she realizes that the Nijinsky performance was inspired by a Thai dance company that choreographer Mikhail Fokine had seen ten years earlier. This Möbius-strip-like movement of performance crossed the twentieth and twenty-first centuries, where imperialism and industrialism allowed for the movement between East and West while artists from different parts of the globe inspired each other, in some cases through misreading created by intentionally altered texts. Leonhardt is careful to document the ways in which the power relations are not equal - these are neither exchanges she documents, nor are they really a balance of import and export - instead, they are refractions of the inequities of global politics.

From the profoundly global explorations of Leonhardt's article, this issue of Theatre Research International moves to interrogate specifically local implementation of an internationally circulating performance pedagogy. Yonghee Lee takes an autoethnographic approach to theorize her participation in a Theatre of the Oppressed (TO) workshop. In 'Theatre for the Less Oppressed than I: Reconsidering Augusto Boal's 
Concept of Spect-actor' she works from her own experiences to offer a critique of some of the practices of forum theatre, in particular the notions of democracy it espouses. In this article she poses careful questions about the efficacy of a process when it cannot account for or accommodate divergent languages and identities. While TO has enormous value and the author embraces its goals, questions remain about its methods, about its notions of 'becoming'. How can participants transform themselves from presences in the room to active participants if there are specific barriers to doing so? She struggles over how TO itself might be transformed to embrace those whose identities are not easily assimilated into the TO approach. Lee is not advocating a rejection of TO; on the contrary, it remains central to her own practices as a teacher, scholar and artist. What this article does offer, however, is a way to adapt those methodologies to more complex and challenging sets of circumstances than ones originally envisioned by Boal and his early collaborators.

Lee examines the challenges of gathering people from all over the globe and compelling them to become and perform. Margaret Ames's discussion of the specifically local work of a Welsh dance company demonstrates that performance is difficult to create and theorize even when it is made by those who share deep commonalities like place. 'Dancing Place/Disability' offers readers an example of how location may be danced and how performance is a restorative act. Margaret Ames focuses on Capel: The Lights are On, a recent work created by Cyrff Ystwyth, of which she is a member. Cyrff Ystwyth has a diverse remit. The group is invested in exploring Welsh rural folkways (many of which are disappearing), disability in performance and practice-based research. These are three very demanding and complex trajectories, even when considered singularly. Ames demonstrates, however, that they are complementary subjects and forms of inquiry. The work studied here offers an exploration of notions of stillness, especially as theorized by dance scholar André Lepecki, not stillness as an absence of movement but, as she puts it, stillness 'by means of agency embodied through gesture'. Cyrff Ystwyth works with dancers who have a range of bodily abilities, so stillness is not the same for each performer. The audience witnesses the performers, particularly choreographer Adrian Jones, who is also in Capel, work to articulate their own versions of stillness. This diversity of ability is juxtaposed with their shared place to offer audiences an opportunity to compare their own diverse and shared histories with those onstage and use the company's work to define (or redefine) their own place in the world.

Of the four articles in this issue, 'Carnivalesque Homoeroticism in Medieval Decadent Cairo: Ibn Dāniyāl's The Love-Stricken One and the Lost One Who Inspires Passion' by Safi Mahmoud Mahfouz will probably be the least familiar to regular readers. Less so because of geography (Egypt) or performance form (shadow puppetry), than because it focuses on a thirteenth-century playwright, Ibn Dāniyāl. TRI is not primarily a historical journal and does not usually publish work that is solely focused on a historical subject. But this article acquaints TRI readers with a figure who should be well known in world literature and yet is not. This knowledge will allow us to adapt our current theatre practices and scholarly methodologies to account for this exciting play. The article is less interested in why we know little about him than in making the case for why we should know Ibn Dāniyāl's dynamic, earthy and hilarious work. Mahfouz starts with the assumption that carnivalesque homoeroticism was a prevalent theme throughout the 
medieval world, not just in Western Europe. Exploring Ibn Dāniyāl's shadow play, The Love-Stricken One and the Lost One Who Inspires Passion, through the lens of Mikhail Bakhtin's theories of the carnivalesque, Mahfouz argues that this play (as well as two others that with it form a trilogy) deserves a more prominent place in theatre history and literature. While largely ignored by scholars until the twentieth century, this ribald play demonstrates how theatre played a part in creating resistance to government repression of sexual practices. This play also extends our knowledge about the use and influence of pornography in everyday life.

As I wrote at the start of this editorial, these are four very different articles. The value of a journal like TRI, dedicated as it is to exploring 'the evolving diversity of critical idioms prevalent in the scholarship of differing world contexts', as its mission statement defines, is that it requires us to define what we mean by terms that frequent performance scholarship - 'process', 'connection' or 'collaboration' - every time we use them. Most importantly, articles like these, taken as a single unit, push at the boundaries of what we think we know and how we think we know it. Whatever trajectory readers plot through these pieces, they will come away thinking very differently about performance than they did previously. 